\title{
Teenage Uploaders on YouTube: Networked Public Expectancies, Online Feedback Preference, and Received On-Platform Feedback
}

\author{
Cédric Courtois, M.A., Peter Mechant, M.A., and Lieven De Marez, Ph.D.
}

\begin{abstract}
This article focuses on teenage YouTube uploaders' networked public expectancies when posting a video. These expectancies allow uploaders to cope temporarily with the uncertainty of who exactly will view their video. The results indicate that teenage uploaders strongly expect viewers that are situated close to them in both geographic and socio-demographic terms. Furthermore, we discuss the uncertainty-reducing properties of online feedback. We propose that different types of online feedback are preferred to verify the prior networked public expectancies. An effect of the identified online public expectancy (viewers with a similar interest/activity) is found for the importance of feedback both on the platform (e.g., views, comments) and off the platform (e.g., interaction on a social-network site). The identified offline public expectancy (friends/ family) affects the importance attributed to off-platform feedback. Surprisingly, no effect of the unidentified online public expectancy (the general public) was found on on-platform feedback. This finding, in conjunction with the low expectancy of this group, raises the question of whether teenagers either cannot conceive this ambiguous mass public, or, if their expectancies are accurate, whether they are aware of the fact that only a small fraction of the videos on YouTube reach notable popularity. Therefore, in a second study, we test the accuracy of the online networked public expectancies by testing their effects on the longitudinal growth of actual feedback (views, comments, and rates). The results provide modest evidence that teenage uploaders have accurate online public expectancies.
\end{abstract}

\section{Introduction}

$\mathbf{R}$ ECENTLY, THE INTERNET HAS EVOLVED into an interactive and expressive medium affording various types of usergenerated content. One of the most popular platforms for doing so is the video-sharing site YouTube, with a daily traffic value reaching $20 \%$ of the Internet population. ${ }^{1}$ Statistics show that YouTube uploaders have an average age of 27 years, indicating that the platform is especially popular with a young audience. ${ }^{2}$ In addition, a recent study has shown that $17 \%$ of teenagers frequently engage in sharing media content, including video clips. ${ }^{3}$

When posting a video, uploaders have no exact knowledge of who their viewers will be. Yet, previous research has shown that YouTube uploaders temporarily cope with this by forming a multidimensional expectancy of their video's networked public, ${ }^{4}$ a concept referring to an actively engaged online audience. This expectancy consists of a combination of three distinct networked public subtypes.
Drawing upon the uncertainty reduction theory, ${ }^{5}$ we argue that feedback is crucial in identifying a video's actual networked public. It enables the uploaders to verify the accuracy of their expectations and even engage in richer forms of computer-mediated communication (CMC). However, modes of feedback strongly differ in characteristics. Our first research goal is, therefore, to investigate what type of feedback is most preferred for what kind of networked public type.

Second, in a follow-up study, we validate the accuracy of the uploaders' online networked public expectancies. Through a longitudinal study of received on-platform feedback (views, rates, and comments), we investigate whether uploaders with a stronger expectancy of the online networked public receive more feedback over time.

\section{The Networked Public}

CMC is commonly classified into (a)synchronous oneto-one and one-to-many communication. ${ }^{6}$ The first type is 
usually characterized by knowledge of the communication partner (e.g., e-mail), where one-to-many communication is far less transparent. For example, when posting a tweet on Twitter, the sender has no absolute certainty of the message's recipients.

The existence of an invisible audience is an essential characteristic of what Ito $^{7}$ and Boyd ${ }^{8,9}$ refer to as "the networked public." This concept entails (a) a space constructed through networked technologies, and (b) the imagined community that (may) emerge there. Moreover, the networked public is seen as active and critically engaged, rather than as a passive audience. Besides invisible audiences, two additional dynamics are noted: a blurring of what is considered public or private, and the absence of a clear-cut communication context. The latter problem is distinguished as a "context collapse": the absence of the familiar boundaries that assist communicators in finding the context of their messages. ${ }^{10}$ Marwick and Boyd ${ }^{11}$ argue that an audience is imagined for every communicative act. The absence of a defined context in one-to-many CMC causes a predicament for communicators who need a more specific conception of their audience than a mere "anyone." As a matter of fact, recent inductive and qualitative research on YouTube has indicated that uploaders do indeed compile a surrogate concept of their potential viewers. ${ }^{4}$ This is concretized in an expectancy pattern for each video.

The perceptions of YouTube uploaders regarding the networked public are two-dimensional (Figure 1). The first dimension (identified vs. unidentified) refers to the degree to which the uploader has a clear, delineated concept of his or her viewers. In turn, the second dimension (offline vs. online) refers to the uploader's social connection with the viewers. In the case of an offline networked public, the uploader shares a physical acquaintance with the viewers. Conversely, there is no physical connection with strictly online viewers (online networked public).

These induced dimensions yield three empirically verified, non-exclusive subtypes of the networked public: (a) the identified offline public, (b) the identified online public, and (c) the unidentified online public. ${ }^{4}$ The identified offline public consists of people with whom the uploader shares a physical acquaintance (friends/family). Uploaders have a clear concept of the behavior and preferences of this group. In terms of social-network edges, this networked public type is characterized by strong ties ${ }^{12}$ and a high degree of social embeddedness. ${ }^{13}$ This is contrary to the offline public, to whom no physical connection is shared with the identified

Offline versus Online

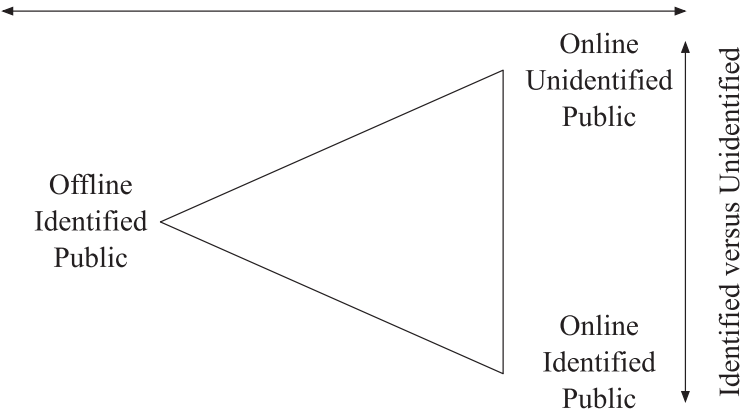

FIG. 1. Networked public dimensions. online public. The uploader has a rather clear concept of this virtual in-group, as they share a similar interest or practice, such as a hobby or a common interest (communities of practice ${ }^{14} /$ communities of interest ${ }^{15}$ ). Finally, the unidentified online public consists of all viewers on YouTube not belonging to an identified networked public. This out-group consists of people the uploader is not familiar with. They share no physical or virtual social bond, social ties of any sort are absent, ${ }^{12}$ and there is no delineated concept of this public's composition.

Courtois et al.'s ${ }^{4}$ results suggest that because of the variable degree of representational salience, the identified public type expectancies are stronger than the unidentified online public expectancy. Furthermore, given the variable degree of social embeddedness, it is assumed that the uploaders expect the offline public more strongly than the online networked publics. Hence, we hypothesize that, on average:

H1a: Uploaders have a stronger expectancy of both identified public types than of the unidentified public type.

H1b: Uploaders have a stronger expectancy of the offline public type than of both online public types.

\section{The Role of Feedback}

Face-to-face communication is usually interspersed with a largely diverse presence of verbal and visual cues, which informs the communicators about their messages' reception. ${ }^{16,17}$ These artificial means of feedback are entirely important in one-to-many CMC, as they serve a double role. Not only do they afford appraisal information (as in one-to-one $\mathrm{CMC}$ ), they also offer cues to identity, making the recipients visible for the communicator. This links in with the Uncertainty Reduction Theory, ${ }^{5}$ which states that people seek information to "reduce ambiguity about that situation by seeking information pertaining to that specific environment."18(p752)

To accomplish this goal, various types of uncertainty reduction strategies (URS) are used. ${ }^{19}$ A recent study ${ }^{20}$ on social-network sites (SNS) has shown that three URS are actually used to gain information on people recently met online: (a) passive URS (e.g., inspecting a profile), (b) active URS (e.g., asking a friend), and (c) interactive URS (e.g., sending private messages). As Lange ${ }^{21}$ has shown, YouTube is used to form new friendship connections and to extend the online social network. Therefore, these URS strategies are likely to apply to YouTube as well. Moreover, research has shown that teenagers use the Internet as a playground on which they can display their selves to others and experiment with their identity. ${ }^{22,23}$ Online, they try out different identities, ${ }^{24,25}$ communicate their tastes and preferences, ${ }^{26}$ and display their social network. ${ }^{8,23}$ However, feedback from relevant sources is required to test the effectiveness of these identity claims. $^{27-30}$ Gathering feedback information allows uploaders to test the accuracy of their personal networked public expectancies. We must acknowledge the diversity of the feedback channels associated with uploading on YouTube, dividing them in two types: on- and off-platform feedback.

The first type refers to cues of attendance and appraisal on the YouTube platform itself (e.g., views/ratings/comments). Hence, they are visible for all viewers and should therefore be seen as one-to-many communication on the viewer's behalf. 
Although this mode of feedback is accessible to every online video viewer, we only expect effects of the online networked public because on-platform feedback is their only possible means to communicate:

H2a: The online identified public expectancy positively predicts the importance that is attributed to online on-platform feedback.

H2b: The online unidentified public expectancy positively predicts the importance that is attributed to online on-platform feedback.

Due to the degree of social embeddedness, and drawing upon earlier findings, ${ }^{4}$ we predict that an identified offline public expectancy is indeed positively associated with the second type of feedback (off-platform feedback). This type of feedback encompasses various external online means of personal, one-to-one communication through other kinds of applications (e.g., Instant Messaging) and platforms (e.g., SNS). To receive this kind of feedback, a formal connection must exist between the uploader and the viewer (e.g., a friend connection on SNS). In line with Subrahmanyam et al., ${ }^{31}$ we hypothesize that this connection already exists with the identified offline public type and that, as such, it serves as a positive predictor of the importance that uploaders attribute to off-platform feedback:

H2c: The offline identified public expectancy positively predicts the importance attributed to online off-platform feedback.

Also, as the identified online public type is quite close to the uploader and URS can be used, there is a likelihood that off-platform communication will emerge. Hence, a fourth hypothesis is added:

H2d: The online identified public expectancy positively predicts the importance attributed to online off-platform feedback.

\section{Study One}

\section{Method}

Data collection and sample. Study one comprises a crosssectional online survey administered in December 2009. YouTube uploaders from 12 to 18 years old were randomly selected from YouTube's Dutch "Most Recent" RSS feed. The selected respondents were sent a comment on their freshly uploaded video, inviting them to participate. Approximately 1,500 invitations were sent. The online survey, completed by 242 teenagers, was entirely focused on the respondent's most recent video. Table 1 provides a sample description.

Measures. The networked publics' expectancies were measured using 5-point Likert statements ("strongly disagree" to "strongly agree"). The items were based on Courtois et al. ${ }^{4}$ The identified offline public expectancy was measured by two items concerning offline friends and family $(\alpha=0.66)$. Likewise, the identified online public consisted of two items regarding people who one is not acquainted with, but with whom one shares a common interest or activity $(\alpha=0.72)$. The unidentified online public was measured by a single item (see Appendix).

Feedback importance was measured using 5-point Likert statements ("absolutely not important" to "absolutely important $t^{\prime \prime}$. The respondents were asked to rate the importance
TAble 1. SAmple Description (Except for Age AND GeNDER, THE DATA WAs ExtRacted FROM THE GOOGLE API)

\begin{tabular}{lrrrr}
\hline $\begin{array}{l}\text { Variable Gender } \\
\text { (63\% Male, }\end{array}$ & & & & \\
$37 \%$ Female) & $\mathrm{M}$ & \multicolumn{1}{c}{ SD } & Skew & Kurtosis \\
\hline Age & 15.04 & 1.69 & 0.09 & -0.96 \\
$\begin{array}{l}\text { Months since having } \\
\text { an account }\end{array}$ & 4.69 & 3.83 & 0.46 & -0.92 \\
$\begin{array}{l}\text { Uploaded videos } \\
\text { Added contacts }\end{array}$ & 39.89 & 70.59 & 5.59 & 36.79 \\
$\begin{array}{l}\text { Number of channel } \\
\quad \text { subscribers }\end{array}$ & 62.50 & 551.99 & 14.69 & 222.30 \\
$\begin{array}{l}\text { Number of channel } \\
\quad \text { views }\end{array}$ & $2,338.42$ & 725.29 & 9.10 & 103.47 \\
$\quad$ Number of video & $5,648.48$ & $7,514.39$ & 3.04 & 13.15 \\
$\quad$ views & & & & \\
\hline
\end{tabular}

of feedback on their most recent video. Off-platform feedback comprised two items: a reaction via Instant Messenger and a reaction on a SNS $(\alpha=0.78)$. On-platform feedback consisted of four items: a comment on YouTube, a large number of views, a large number of ratings, and a high average rating $(\alpha=0.90)$.

\section{Results}

Hypotheses $1 \mathrm{a}$ and $\mathrm{b}$ were tested using a one-way withinsubjects ANOVA, employing the networked public types as within-subjects variables. The analysis indicates an effect of public type, $\left.F(2,460)=62.90, p<0.001, \eta_{\mathrm{p}}{ }^{2}=0.21\right)$. Descriptives and pairwise contrasts are summarized in Table 2 . These results support H1a, predicting higher identified public expectancies. However, H1b is only partially confirmed: on average, the offline identified public is indeed more strongly expected than the unidentified online public, while the online identified public is more strongly expected than the offline public.

To test the remaining hypotheses, a structural equation model was computed, yielding an excellent model fit, $\chi^{2}(37)=51.25, p>0.05, \mathrm{TLI}=0.98, \mathrm{CFI}=0.99, \mathrm{RMSEA}=0.04$. The manifest variables' raw correlations are included in the Appendix.

The standardized path coefficients in Figure 2 provide evidence for all but one hypothesis. We found that an identified online public expectancy positively predicts on-platform feedback importance, confirming H2a. An unidentified online public expectancy does not, however, predict on-platform feedback importance, which disconfirms H2b. Additionally, evidence is found for $\mathrm{H} 2 \mathrm{c}$, which states that an offline identified public expectancy positively affects off-platform feedback importance. Likewise, an identified online public expectancy positively predicts online off-platform feedback importance, confirming $\mathrm{H} 2 \mathrm{~d}$.

Table 3 provides an overview of study one's hypotheses.

\section{Discussion}

The results clearly demonstrate that at the moment of upload, teenage uploaders have stronger expectancies of networked public types that are situated closer to the self in both a geographic and a socio-demographic sense. Uploaders presume that familiar people will watch their clips and 
Table 2. Networked Public Descriptives and Pairwise Contrasts

\begin{tabular}{|c|c|c|c|c|}
\hline \multirow{2}{*}{$\begin{array}{l}\text { Descriptives } \\
\text { Public type }\end{array}$} & \multirow[b]{2}{*}{$\mathrm{M}$} & \multirow[b]{2}{*}{ SD } & \multicolumn{2}{|l|}{ Pairwise contrasts } \\
\hline & & & Contrast pairs & Paired t(241) \\
\hline Offline identified & 3.60 & 0.98 & Offline identified-online identified & $-3.05^{* *}$ \\
\hline Online identified & 3.88 & 0.87 & Offline identified-unidentified online & $7.44^{* * *}$ \\
\hline Online unidentified & 2.96 & 1.08 & Online identified-online unidentified & $12.31^{* * *}$ \\
\hline
\end{tabular}

${ }^{* *} p<0.005 ; * * * p<0.001$.

provide feedback through informal off-platform channels. This indicates a pragmatic use of YouTube as an easily accessible storage place. However, the strongest expectancy is that of the online identified public. This in-group of strangers, with whom an interest or activity is shared, is not always easy to locate in an offline setting. This suggests that teenagers intend to use YouTube as a means to get to know new people. As both types of feedback are given equal importance, we suspect that uploaders wish to instigate a closer contact with these people. Yet, before off-platform feedback can be received, a formal connection needs to be established. This demonstrates the importance of receiving feedback, as the cues to identity provided on the platform enable various forms of URS that are crucial to get to know each other.

Perhaps one of the most striking findings is the low expectancy score for the unidentified online public. Even so, there is no effect of this public type on feedback importance.
This suggests that teenagers do not really care about this group and its feedback. We propose two possible explanations for this occurrence. First, it is possible that the online unidentified public is too ambiguous, too difficult to conceive, and is therefore mainly ignored. The second links in with Marwick and Boyd's claim that our understanding of social media is limited. ${ }^{11}$

An opposing explanation is the possibility that teenagers have a realistic expectancy of what their public might be. Previous research has shown that $10 \%$ of YouTube's videos account for $80 \%$ of the views. ${ }^{32}$ Withal, although the majority of YouTube's content is user generated, it is a small minority of professionally generated videos that attain a large audience. ${ }^{33}$ Hence, we propose the possibility that teenagers have a notion of the small odds that their video will become popular and therefore do not care much about the unidentified online public.

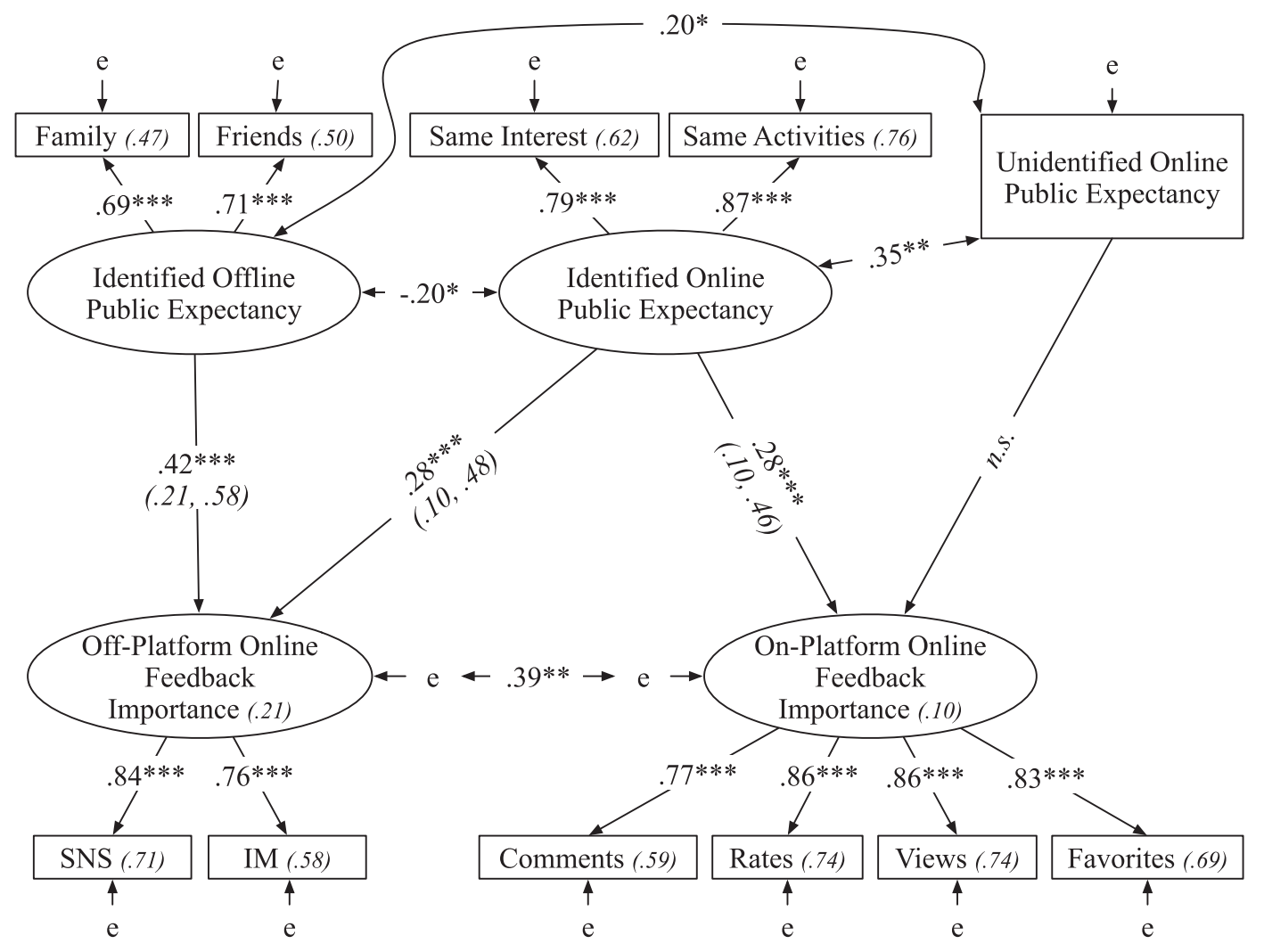

FIG. 2. Structural model with standardized estimates, ${ }^{*} p<0.05,{ }^{* *} p<0.005,{ }^{* * *} p<0.001$. Multiple squared correlations are included in italics. 95\% bias-corrected confidence intervals, obtained by a bootstrap procedure, are included in parentheses. The feedback modes' error terms were allowed to correlate, as common factors are assumed to explain additional variance in these variables. 
Table 3. Hypotheses Study One

\begin{tabular}{|c|c|c|}
\hline Hypotheses & & \\
\hline H1a & $\begin{array}{l}\text { On average, YouTube uploaders } \\
\text { have a stronger expectancy } \\
\text { of both identified public } \\
\text { types than the unidentified } \\
\text { public type. }\end{array}$ & Confirmed \\
\hline $\mathrm{H} 1 \mathrm{~b}$ & $\begin{array}{l}\text { On average, YouTube uploaders } \\
\text { have a stronger expectancy } \\
\text { of the offline public type than } \\
\text { both online public types. }\end{array}$ & $\begin{array}{l}\text { Partially } \\
\text { confirmed }\end{array}$ \\
\hline $\mathrm{H} 2 \mathrm{a}$ & $\begin{array}{l}\text { The online identified public } \\
\text { expectancy positively } \\
\text { predicts the importance } \\
\text { attributed to online } \\
\text { on-platform feedback. }\end{array}$ & Confirmed \\
\hline $\mathrm{H} 2 \mathrm{~b}$ & $\begin{array}{l}\text { The online unidentified public } \\
\text { expectancy positively } \\
\text { predicts the importance } \\
\text { attributed to online } \\
\text { on-platform feedback. }\end{array}$ & Disconfirmed \\
\hline $\mathrm{H} 2 \mathrm{c}$ & $\begin{array}{l}\text { The offline identified public } \\
\text { expectancy positively } \\
\text { predicts the importance } \\
\text { attributed to online } \\
\text { off-platform feedback. }\end{array}$ & Confirmed \\
\hline $\mathrm{H} 2 \mathrm{~d}$ & $\begin{array}{l}\text { The online identified public } \\
\text { expectancy positively } \\
\text { predicts the importance } \\
\text { attributed to online } \\
\text { off-platform feedback. }\end{array}$ & Confirmed \\
\hline
\end{tabular}

If teenagers' expectancies are accurate, then these expectancies should predict actual feedback on the condition that the feedback type is valued for the considered networked public type. In study two, we test this hypothesis for onplatform feedback. In the previous study, we found a positive effect of the identified online public expectancy on this feedback type, while-although hypothesized-no effect was found for the unidentified online public expectancy. Therefore, we propose an effect on the eventual increase of actual feedback of the former and no effect of the latter. The offline identified public is not included in study two due to the fact that there is no direct conceptual or empirical link with on-platform feedback, $r(240)=0.07, p=0.28$. Table 4 summarizes the hypotheses.

\section{Study Two}

\section{Method}

Data collection and analysis method. This study consists of the latent growth analysis $\left(\mathrm{LGM}^{34}\right)$ of the actual number of received views, comments, and ratings on study one's respondents' most recent video. The technique of $\mathrm{LGM}^{34}$ is used because it enables the simultaneous assessment of the over time effects of both online public expectancies on the increase of feedback. Moreover, a longitudinal study allows us to determine whether the effects are stable and not concentrated in a specific time frame.

The data were gathered by collecting public data from Google's API at three separate moments. Wave one took place 2 weeks after study one was terminated. Waves two and three
Table 4. Hypotheses Study Two

\section{Hypotheses}

H3a The expectancy of an online identified public positively affects the over time quantity and increase of a video's number of views

$\mathrm{H} 3 \mathrm{~b}$

The expectancy of an online unidentified public positively does not affect the over time quantity and increase of a video's number of views

$\mathrm{H} 3 \mathrm{c}$

The expectancy of an online identified public positively affects the over time quantity and increase of a video's number of comments

$\mathrm{H} 3 \mathrm{~d}$

The expectancy of an online unidentified public positively does not affect the over time quantity and increase of a video's number of comments

$\mathrm{H} 3 \mathrm{e}$

The expectancy of an online identified public positively affects the over time quantity and increase of a video's number of ratings

H3f

The expectancy of an online unidentified public positively does not affect the over time quantity and increase of a video's number of ratings

took place at a fixed interval of 1 and 2 months respectively following wave one. On average, 23.64 days elapsed between the video upload and the first data collection. This interval does not correlate with the online networked public scores, $r(240)=0.02,0.05, p>0.05$. The absence of a relationship indicates that a bias in the time interval is unlikely.

\section{Results}

All three models (Figure 3), one for each feedback type, yield an absolute goodness of fit. The results in Table 5 should

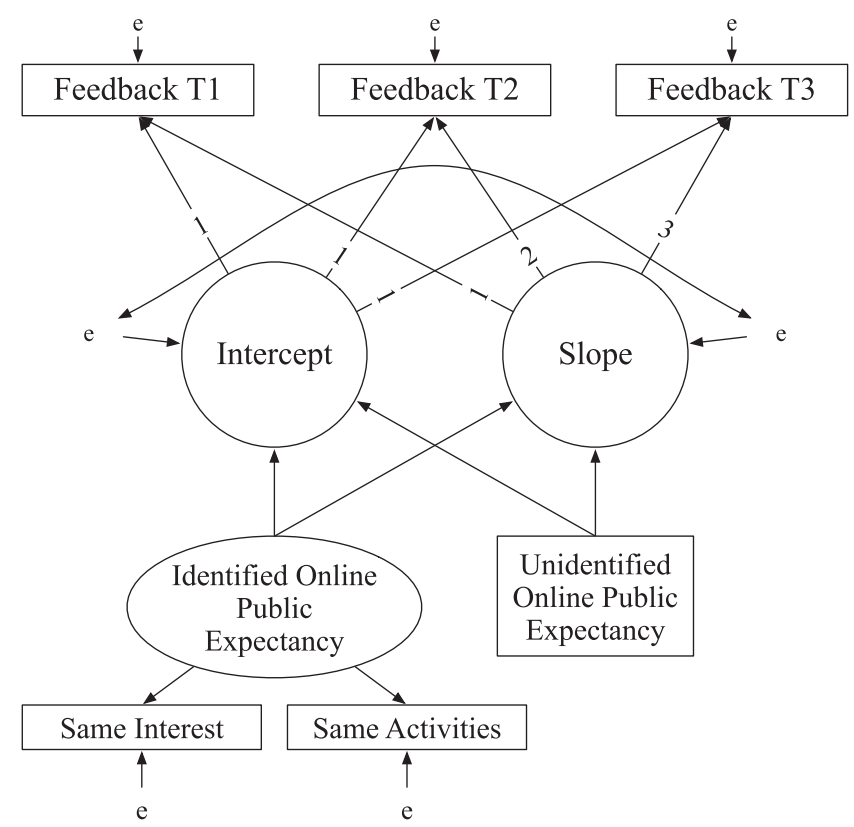

FIG. 3. Specified conditional linear growth model. 
TAble 5. LGM Analysis Summary

\begin{tabular}{lclrrl}
\hline Feedback & Model fit $\chi^{2}(6), \mathrm{p}$ & & Intercept & Slope & Hypothesis \\
\hline Views & \multirow{2}{*}{$4.45,0.48$} & Model parameters: & 215.22 & 30.71 & \\
& & Effect of online identified public expectancy on: & $73.67^{*}$ & 14.59 & H3a: partially confirmed \\
& & Effect of online unidentified public expectancy on: & $-51.09^{*}$ & 17.87 & H3b: partially confirmed \\
Comments & $5.16,0.52$ & Model parameters: & 6.33 & 0.16 & \\
& & Effect of online identified public expectancy on: & $2.72^{* *}$ & 0.18 & H3c: partially confirmed \\
& & Effect of online unidentified public expectancy on: & -1.00 & 0.07 & H3d: confirmed \\
Ratings & \multirow{2}{*}{$0.88,0.99$} & Model parameters: & 10.05 & 1.01 & \\
& & Effect of online identified public expectancy on: & $4.71^{*}$ & $0.25^{*}$ H3e: confirmed \\
& & Effect of online unidentified public expectancy on: & -2.54 & -0.18 & H3f: confirmed \\
\hline
\end{tabular}

${ }^{*} p<0.05 ;{ }^{* *} p<0.01$.

be interpreted as follows: a model's intercept represents the value of a measure at the start of the process, while a model's slope represents the average change of the measure per time unit. Consequently, a significant intercept difference indicates a substantial effect of the online public(s) on the feedback received between upload and the first API data collection. When the slope is also significant, it indicates that the difference continues to increase.

\section{Discussion}

We proposed two possible explanations for the low expectancy of the unidentified online public and the lack of a relation with the importance attributed to on-platform feedback. Study two provides modest evidence regarding the explanation that teenagers' expectancies of the online publics are accurate. Uploaders with a higher expectancy of the online identified public indeed receive more feedback, although only a significantly larger growth pertains to ratings. The expectancy of an online unidentified public does not affect the amount of received feedback (with the exception of a lower amount of views). Yet, the uploaders reported low expectancies of this public type and indicated that they did not care about their feedback.

\section{Conclusion}

By drawing upon previous in-depth research and operationalizing its measures, the present article illuminates the expectancies of teenagers' networked public on YouTube, the feedback they rely on to verify their expectancies, and the actual accuracy of these expectancies. Our findings support the proposal that for every communicative act, a public is expected. More specifically, the results indicate that teenagers upload for a limited amount of people, rather than for a global audience. Those who do aim for a large audience receive fewer views and are likely forced to alter their beliefs. Still, in general, we are able to conclude that teenagers have an accurate, moderate, and realistic view on the YouTube phenomenon and use it in a practical way: to share videos with people who are situated (relatively) close to them. As such, by shedding light on teenagers' beliefs and practices regarding their online activities, we believe these findings contribute to the ongoing debate concerning teenage new media literacy. ${ }^{35}$

This article also serves to demonstrate the strengths of using multiple data sources. However, several limitations, such as reliability issues in online surveys and a possible self-selection bias, need to be taken into account. ${ }^{32}$ Nonetheless, we hope that this study will be used as a point of departure for further research. For example, we did not address the accuracy of the offline public expectancy by investigating off-platform feedback. For this matter, we propose the use of diaries. Also, we recommend replications in other geographical contexts, for different types of user-generated content, platforms, and subject groups. Finally, we propose extensions by means of contextualizing qualitative research.

\section{Acknowledgments}

We would like to thank Joris Willems for his help in programming the study's selection application. We also thank Katarina Panić and Jeroen Stragier for their helpful comments on an earlier version of the manuscript.

\section{Disclosure Statement}

No competing financial interests exist.

\section{References}

1. Alexa (2009) Youtube.com-Traffic details from Alexa. www .alexa.com/siteinfo/youtube.com (accessed Aug. 3, 2010).

2. Wesch M. (2008) YouTube Statistics. http://mediatedcultures. net $/ \mathrm{ksudigg} / \mathrm{p}=163$ (accessed Aug. 3, 2010).

3. Courtois C, Mechant P, De Marez L, et al. Gratifications and seeding behavior of online adolescents. Journal of ComputerMediated Communication 2009; 15:109-37.

4. Courtois C, Ostyn V, Mechant P (2009). YouTube: Sharing AV content as a collective effort. Paper presented at the CMI International Conference on Social Networking and Communities, Copenhagen.

5. Berger CR, Calabrese RJ. Some explorations in initial interaction and beyond: Toward a developmental theory of interpersonal communication. Human Communication Research 1975; 1:99-112.

6. Baron NS. Language of the Internet. In Farghali A, ed. The Stanford handbook for language engineers. Stanford, CA: CSLI Publications, pp. 59-127.

7. Ito M. (2008) Introduction. In Varnelis K, ed. Networked publics. Cambridge, MA: MIT Press, pp. 1-14.

8. Boyd D. (2008) Why youth (heart) social network sites: The role of networked publics in teenage social life. In Buckenham D, ed. Youth, identity, and digital media. Cambridge, MA: MIT Press, pp. 119-42.

9. Boyd D. (2008) Taken out of context: American teen sociality in networked publics. Berkeley: University of California, Berkeley. 
10. Wesch M. (2008) Context collapse. http://mediatedcultures. net $/ \mathrm{ksudigg} / \mathrm{?}=183$ (accessed Aug. 3, 2010).

11. Marwick AE, Boyd D. I tweet honestly, I tweet passionately: Twitter users, context collapse, and the imagined audience. New Media \& Society [Epub ahead of print]; DOI:10.1177/ 1461444-810365-313.

12. Granovetter MS. The strength of weak of weak ties. The American Journal of Sociology 1973; 78:1360-80.

13. Matzat U. A Theory of Relational Signals in Online Groups. New Media \& Society 2009; 11:375-94.

14. Wenger E. (1998) Communities of practice: Learning, meaning, and identity. Cambridge, England: Cambridge University Press.

15. Armstrong A, Hagel J. The real value of online communities. Harvard Business Review 1996; 74:134-41.

16. Culnan M, Markus M. (1987) Information technologies. In Jablin F, Putnam R, Roberts K, Porter L, eds. Handbook of organizational communication: An interdisciplinary perspective. Thousand Oaks, CA: Sage, pp. 420-43.

17. Sia C-L, Tan BCY, Wei K-K. Group polarization and computermediated communication: Effects of communication cues, social presence, and anonymity. Information Systems Research 2002; 13:70-90.

18. Westerman D, van Der Heide B, Klein KA, et al. How do people really seek information about others?: Information seeking across Internet and traditional communication channels. Journal of Computer-Mediated Communication 2008; 13:751-67.

19. Tidwel LC, Walther JB. Computer-mediated communication effects on disclosure, impressions, and interpersonal evaluations. Getting to know one another a bit at a time. Human Communication Research 2002; 28:317-48.

20. Antheunis ML, Valkenburg PM, Peter J. Getting acquainted through social network sites: Testing a model of online uncertainty reduction and social attraction. Computers in Human Behavior 2010; 26:100-9.

21. Lange PG. Publicly private and privately public: Social networking on YouTube. Journal of Computer-Mediated Communication 2008; 13:361-80.

22. Thomas A. (2007) Youth online: Identity and literacy in the digital age. New York: Peter Lang.

23. Livingstone S. Taking risky opportunities in youthful content creation: Teenagers' use of social networking sites for intimacy, privacy and self-expression. New Media \& Society 2008; 10:393-411.

24. Gross EF. Adolescent Internet use: What we expect, what teens report. Applied Developmental Psychology 2004; 25:633-49.
25. Valkenburg P, Schouten A, Peter J. Adolescents' identity experiments on the Internet. New Media \& Society 2005; 7:383-402.

26. Liu H. Social network profiles as taste performances. Journal of Computer-Mediated Communication 2007; 13:252-75.

27. Valkenburg PM, Peter J. Adolescents' identity experiments on the Internet: Consequences for social competence and self-concept unity. Communication Research 2008; 35: 208-31.

28. Schmitt KL, Dayanim S, Matthias S. Personal homepage construction as an expression of social development. Developmental Psychology 2008; 44:496-506.

29. Peter J, Valkenburg PM, Schouten AP. Characteristics and motives of adolescents talking with strangers on the Internet. CyberPsychology \& Behavior 2006; 9:526-30.

30. Valkenburg PM, Peter J. Preadolescents' and adolescents' online communication and their closeness to friends. Developmental Psychology 2007; 43:267-77.

31. Subrahmanyam K, Reich SM, Waechter N, et al. Online and offline social networks: Use of social networking sites by emerging adults. Journal of Applied Developmental Psychology 2008; 29:420-33.

32. Cha M, Kwak H, Ahn YY, et al. (2007) I Tube, You Tube, Everybody Tubes: Analyzing the world's largest user generated content video system. Paper presented at the IMC, San Diego, California.

33. Kruitbosch G, Nack F. (2008) Broadcast yourself on YouTube: Really? Paper presented at the 3rd ACM International Workshop on Human-Centered Computing, New York.

34. Preacher KJ, Wichman AL, MacCullum RC, et al. (2008) Latent growth curve modeling. London: Sage.

35. Jenkins H, Purushotma R, Clinton K, et al. (2009) Confronting the challenges of participatory culture: Media education for the 21st century. Chicago: The MacArthur Foundation.

Address correspondence to: Cédric Courtois, M.A.

IBBT-MICT-Ghent University Department of Communication Sciences

Korte Meer 7-9-11 9000 Ghent Belgium

E-mail: cedric.courtois@ugent.be

\section{Appendix}

Appendix Table 1. Measurement Items

\begin{tabular}{|c|c|c|}
\hline Construct & Item abbreviation & Item \\
\hline \multirow[t]{2}{*}{ Identified offline public } & Family & I expect my family to watch my video clip \\
\hline & Friends & $\begin{array}{l}\text { I expect my real life friends to watch } \\
\text { my video clip }\end{array}$ \\
\hline \multirow[t]{2}{*}{ Identified online public } & Same interest & $\begin{array}{l}\text { I expect YouTube surfers, who I do not know } \\
\text { personally, but with whom I share a similar } \\
\text { interest, to watch my video clip }\end{array}$ \\
\hline & Same activities & $\begin{array}{l}\text { I expect YouTube surfers, who I do not know } \\
\text { personally, but with who engage in activities } \\
\text { similar to my own, to watch my video clip }\end{array}$ \\
\hline Unidentified online public & - & $\begin{array}{l}\text { I expect YouTube surfers, who I do not know } \\
\text { personally and with whom I do not have } \\
\text { something in common, to watch my video clip }\end{array}$ \\
\hline
\end{tabular}


Appendix Table 2. The Model's Manifest Variables' Zero-Order Correlations

\begin{tabular}{|c|c|c|c|c|c|c|c|c|c|c|}
\hline & 1 & 2 & 3 & 4 & 5 & 6 & 7 & 8 & 9 & 10 \\
\hline 1. Family & - & & & & & & & & & \\
\hline 2. Friends & $0.49^{* *}$ & - & & & & & & & & \\
\hline 3. Same interest & $-0.14^{*}$ & -0.12 & - & & & & & & & \\
\hline 4. Same activity & -0.09 & $-0.15^{*}$ & $0.68^{* *}$ & - & & & & & & \\
\hline 5. Unidentified online public & $0.14^{*}$ & 0.11 & $0.26^{* *}$ & $0.30^{* *}$ & - & & & & & \\
\hline 6. Feedback IM & $0.17^{* *}$ & $0.22^{* *}$ & $0.16^{*}$ & $0.15^{*}$ & $0.19^{* *}$ & - & & & & \\
\hline 7. Feedback SNS & $0.25^{* *}$ & $0.23^{* *}$ & 0.10 & 0.12 & $0.21^{* *}$ & $0.64^{* *}$ & - & & & \\
\hline 8. Feedback views & 0.02 & 0.02 & $0.26^{* *}$ & $0.28^{* *}$ & $0.19^{* *}$ & $0.26^{* *}$ & $0.26^{* *}$ & - & & \\
\hline 9. Feedback rating & 0.08 & 0.07 & $0.15^{*}$ & $0.16^{*}$ & $0.14^{*}$ & $0.27^{* *}$ & $0.34^{* *}$ & $0.74^{* *}$ & - & \\
\hline 10. Feedback comment & 0.07 & 0.08 & $0.27^{* *}$ & $0.27^{* *}$ & 0.11 & $0.36^{* *}$ & $0.37^{* *}$ & $0.67^{* *}$ & $0.65^{* *}$ & - \\
\hline 11. Feedback favorite & 0.03 & 0.06 & $0.17^{* *}$ & $0.23^{* *}$ & $0.22^{* *}$ & $0.27^{* *}$ & $0.28^{* *}$ & $0.71^{* *}$ & $0.73^{* *}$ & $0.62^{* *}$ \\
\hline
\end{tabular}

${ }^{*} p<0.05 ;{ }^{* *} p<0.01$. 